\title{
Study of the corrosion properties in a hot forged Cu-Al-Ni alloy with added Cr
}

\author{
${ }^{1}$ Department of Mechanical Engineering, K. Ramakrishnan College of Technology, Samayapuram, Tiruchirapalli 621112, Tamil \\ Nadu, India, Phone: +919080562028, E-mail: parameswaran.krct@gmail.com \\ 2 Tata Consultancy Services Limited, Bangalore 560066, Karnataka, India \\ ${ }^{3}$ Department of Mechanical Engineering, K. Ramakrishnan College of Technology, Samayapuram, Tiruchirapalli 621112, Tamil \\ Nadu, India
}

\begin{abstract}
:
Here, the corrosion properties of chromium $(\mathrm{Cr})$ added to a copper-aluminum-nickel (Cu-Al-Ni) alloy were studied. Primarily, the alloy samples were prepared by increasing the percentages of $\mathrm{Cr}$ composition in the following series of $4 \%, 8 \%$ and $12 \%$ by keeping other alloying elements as constants. The alloy was made using the powder metallurgical technique. Consequently, hot forging was done on the sintered specimen. Both hypothetical and authentic densities were found for the hot forged samples which showed that the densities kept on increasing with the addition of $\mathrm{Cr}$. The $\mathrm{Cr}$ embellishments were exposed using optical microscopy of varying magnifications. The corrosion properties achieved from the potentiostat showed that the corrosion resistance upsurges more than the other commercially available nickel-aluminum-bronze (NAB) alloys due to the $\mathrm{Cr}$ embellishments. The corroded surface was then investigated using scanning electron microscopy (SEM) which disclosed the formation of different $\kappa$ phases along with an $\alpha$ matrix and other intermetallic phases in the present alloy. Furthermore, hardness tests were taken and these established that the hardness increases with $\mathrm{Cr}$ accompaniments. Thus, the present alloy can be endorsed as a novel material ( $\mathrm{Cu}-\mathrm{Al}-\mathrm{Ni}-\mathrm{Cr})$ in the propellers of ships in which both hardness and corrosion resistant are obligatory.
\end{abstract}

Keywords: electro-chemical corrosion, hot-forging, NAB alloy, powder metallurgy, scanning electron microscope DOI: $10.1515 / j m b m-2018-0016$

\section{Introduction}

The nickel-aluminum-bronze (NAB) alloy is the most widely used alloy in highly saline environments due to its superb corrosion resistance. The alloy is mainly composed of nickel (Ni), aluminum (Al) and bronze in moderate amounts along with small amounts of manganese, iron, etc., with copper as the main element which makes it good for ship propellers. The NAB alloy is used in marine equipment, mainly in propellers, pumps, valves, etc. due to its high mechanical properties and admirable corrosion resistance [1], [2], [3], [4], [5]. The microstructures obtained in the NAB alloy are an $\alpha$-copper-rich phase, and various intermetallic phases such as $\beta^{\prime}$ and different $\kappa$ phases which play important roles in the corrosion of the material. The microstructures play an important role in the cavitation corrosion of the material in highly saline water [6]. The phases formed by as-cast NAB are $\kappa$ phases and $\beta^{\prime}$ phases in friction-stirred processed NAB dissolve in $3.5 \% \mathrm{NaCl}$ as they have low resistance to corrosion. The $\mathrm{Al}_{2} \mathrm{O}_{3}$ film formed acts as protective layer in casted NAB [7]. In the continuous $\kappa_{\text {III }}$ phase on the microstructure, when it is exposed to prolonged seawater causes a pitting mechanism outside the crevice area which makes it wide and shallow [8]. The shot peened layer of the NAB alloy revealed that the corrosion rate increased due to the microstructural changes which occurred by strain hardening [9]. The corrosion behavior of the alloy was studied in both a cast and a wrought NAB alloy by open circuit potentiometry. The corrosion characteristics of the NAB alloy was studied in short- and long-term immersion trials [10]. The advantages of the NAB alloy are high ductility, high fracture toughness, higher strength and good resistance to corrosion, particularly in seawater applications [11], [12], [13], [14]. However, due to the formation of $\alpha-\kappa$ phases it suffers erosion-corrosion which were confirmed under microstructures and resisted cavitation [15], [19], [20]. The corrosion resistance due to galvanic coupling was studied and revealed that the pitting corrosion occurred in the NAB alloy [16]. The increase in the corrosion resistance is not superior when the NAB alloy is heat treated. But the hardness value improved due to the generation of hard phases like $\kappa, \beta^{\prime}$ phases [17]. The NAB alloy, even though it had excellent corrosion properties, still it suffered corrosion and we can improve it further. The reason behind this was the Fe-rich phase $\kappa$ phases which are mainly responsible for the corrosion 
initiation. This phase, even though has high hardness, undergoes corrosion [18]. During the corrosion test, dissolution of $\mathrm{Cu}$ occurs in the reaction and this is important for the crevices to increase the surface concentration of $\mathrm{Cu}$ ions. Laser treatment can reduce the crevice [21].

In this study, the corrosion behavior of the Ni-ALalloy along with microstructure were studied in relation to the influence of $\mathrm{Cr}$. The mechanical properties such as the Vickers hardness test were studied.

\section{Material processing}

Fine powders of N, Al, Cu and Cr were imported from Alfa Aeser Private Limited (London, UK) with a 325 mesh and $44 \mu \mathrm{m}$ particle size. Ball milling of the powders of the mentioned compositions (Table 1) were done using high energy ball milling for $10 \mathrm{~h}$ with a dry ball powder ration of 10:1. For the compaction a 1:1 ratio of the specimen has used with cylindrical size of L/D ratio 1 . The fine powder obtained was compressed to get a green billet by using a punch and die in a universal testing machine with the application of $350 \mathrm{kN}$. The specimens were prepared for further sintering by polishing them with grade sheets of coarse to fine quality. Thus, the final specimens for sintering were obtained. Sintering was done in a muffle furnace at $850^{\circ} \mathrm{C}$ and the temperature was maintained for $90 \mathrm{~min}$. Hot forging was done in a hydraulic press.

Table 1: Alloy sample composition.

\begin{tabular}{lrrrr}
\hline Alloy & & & \multicolumn{2}{c}{ Chemical composition (\% weight) } \\
\cline { 2 - 5 } & Copper & Aluminum & Nickel & Chromium \\
\hline Sample A & 82.5 & 9.5 & 4 & 4 \\
Sample B & 78.5 & 9.5 & 4 & 8 \\
Sample C & 74.5 & 9.5 & 4 & 12 \\
\hline
\end{tabular}

The hot forged sample cut into $10 \times 10 \mathrm{~mm}$ with a thickness of $5 \mathrm{~mm}$ and the density was checked by using Archimedes' principle for specimens before and after sintering. The scanning electron microscopy (SEM) images on the corroded area were taken for the study. The Rockwell hardness and micro-Vickers hardness test were conducted on sintered and forged specimens with various compositions. The microstructure was imaged using an optical microscope that was software driven. The specimen was prepared with a sequence of operations that included grinding the specimen with emery sheets followed by polishing with ethanol. An acidified ferric chloride was used for etching the component for a period of $1 \mathrm{~min}$. A potentiostat was used for electro-chemical corrosion to obtain the Tafel plot. An SEM image was recorded on the corroded area. A corrosion test was carried out in a 3.5\% NaCl solution using a potentiostat at the National Institute of Technology - Tiruchirappalli. By analogy we know that the chloride media is responsible for corrosion processes, so a $3.5 \%$ $\mathrm{NaCl}$ solution was used. According to the $\mathrm{Cl}^{-}$ion containing environments, the formation of $\mathrm{CuCl}_{2}^{-}$and $\mathrm{CuCl}_{3}{ }^{-}$ protective layers occurs. $\mathrm{Cu}_{2} \mathrm{O}$ is responsible for localized corrosion which is passivated at a faster rate.

\section{Results and discussion}

\subsection{Density calculation}

Both the theoretical and actual densities of the samples were found using a bulk density tester apparatus. The calculated volume of the compacted specimens was $12.271 \mathrm{~cm}^{3}(\mathrm{~L} / \mathrm{D}=1)$. The densities of the hot forged specimens were found to be higher than the sintered specimens and are listed in Table 2.

Table 2: Density attained at sintering and hot forging.

\begin{tabular}{lrrr}
\hline Sample & Theoretical density & Sintering density & Hot forged density \\
\hline Specimen 1 & 7.2834 & 5.4038 & 6.6 \\
Specimen 2 & 7.2257 & 5.5466 & 6.8 \\
Specimen 3 & 7.1690 & 5.6195 & 6.9 \\
\hline
\end{tabular}




\subsection{Mechanical properties}

For the Rockwell hardness, it is measured on a B-scale intender with load of $100 \mathrm{kgf}, 1 / 16$ inch steel ball intender. Both the Rockwell and micro-hardness reveal that the obtained hardness is much more than for the existing NAB alloys. Thus, the Cr influences increase the hardness of the alloys. From Table 3 and Table 4 , it is clear that the obtained mechanical properties are higher than the existing alloys.

Table 3: Rockwell hardness (B-scale) test result.

\begin{tabular}{lrr}
\hline Sample & Sintered work piece & Hot forged work piece \\
\hline Specimen 1 & 67 & 71 \\
Specimen 2 & 77 & 81 \\
Specimen 3 & 89 & 94 \\
\hline
\end{tabular}

Table 4: Micro-Vickers hardness test result.

\begin{tabular}{lrr}
\hline Sample & Sintered work piece & Hot forged work piece \\
\hline Specimen 1 & 98 & 111 \\
Specimen 2 & 167 & 245 \\
Specimen 3 & 240 & 286 \\
\hline
\end{tabular}

\subsection{Material characterization}

The structure shows the different phases in the compounds which are shown in Figure 1. All the three structures show the $4 \%, 8 \%$ and $12 \%$ of $\mathrm{Cr}$ addition. We can predict that the gray spots in the microstructure show the formation of nichrome. The silvery traces of $\mathrm{Al}$ were also present on the microstructure. The entire image of different composition showed the well distribution of $\mathrm{Cr}$ in the alloys. We found the different phases formed in the alloy by analyzing the optical microstructure.
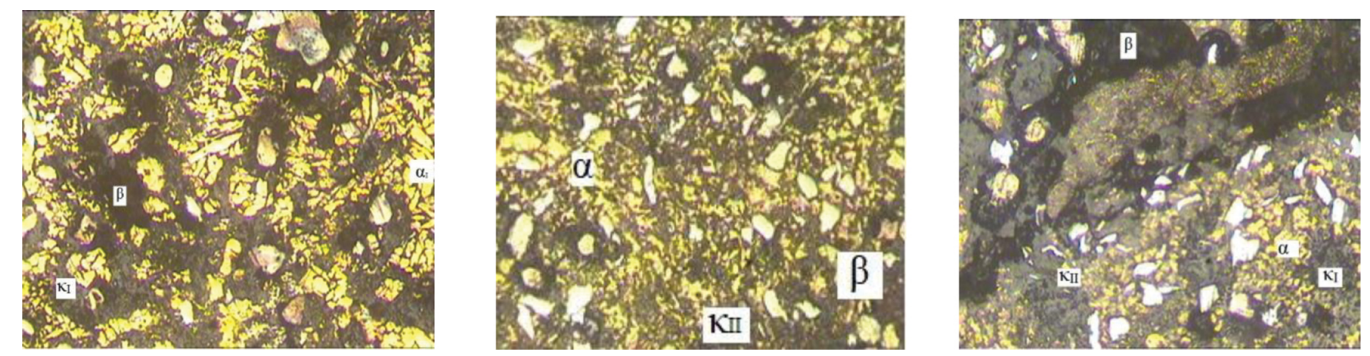

Figure 1: Showing the microstructure of $4 \%, 8 \%$ and $12 \% \mathrm{Cr}$ specimens.

\subsection{Corrosion properties}

The sample was cleaned, polished with grid sheets from lower to higer sizes for obtaining a mirror finish. The potentiostat was used to analyze the accelerated corrosion. The polarization curves are shown in Figure 2 and Figure 3, obtained from the corrosion tests for the $4 \%$ and $8 \% \mathrm{Cr}$ samples. The decreased anodic current in the slope is due to the formation of oxide layers of $\mathrm{Cu}$ and $\mathrm{Al}$. The corrosion resistant properties increased due to the addition of $\mathrm{Cr}$. The corrosion occurs on the $\kappa$ phases. The corrosion properties are tabulated below in Table 5 . 


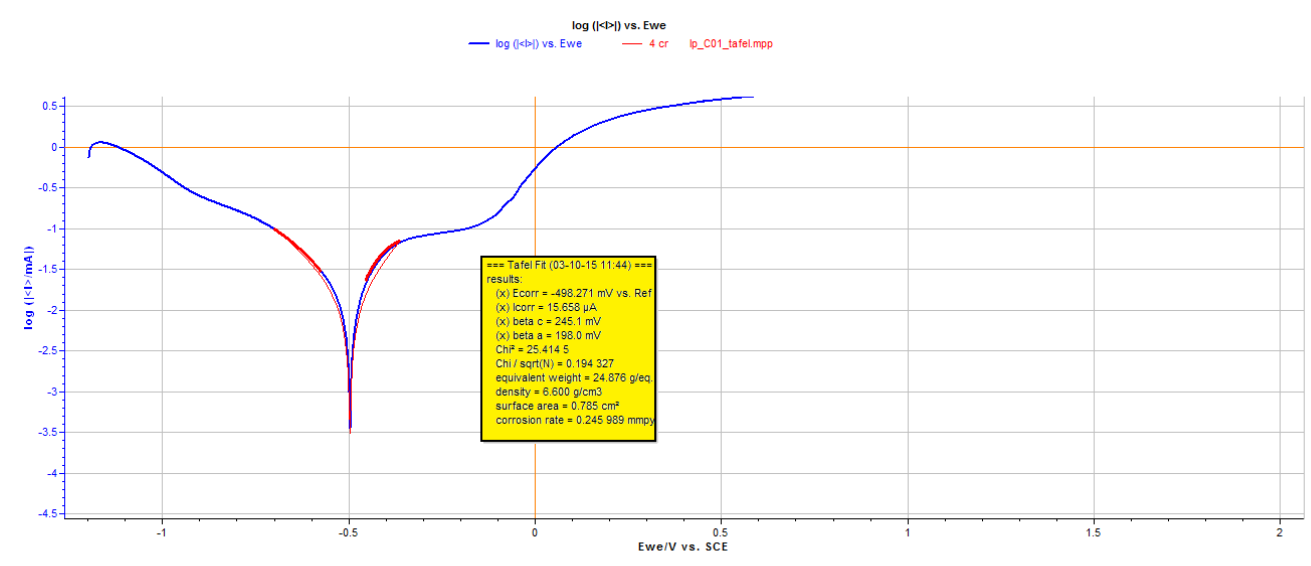

Figure 2: Tafel graph for $4 \%$ Cr specimens.

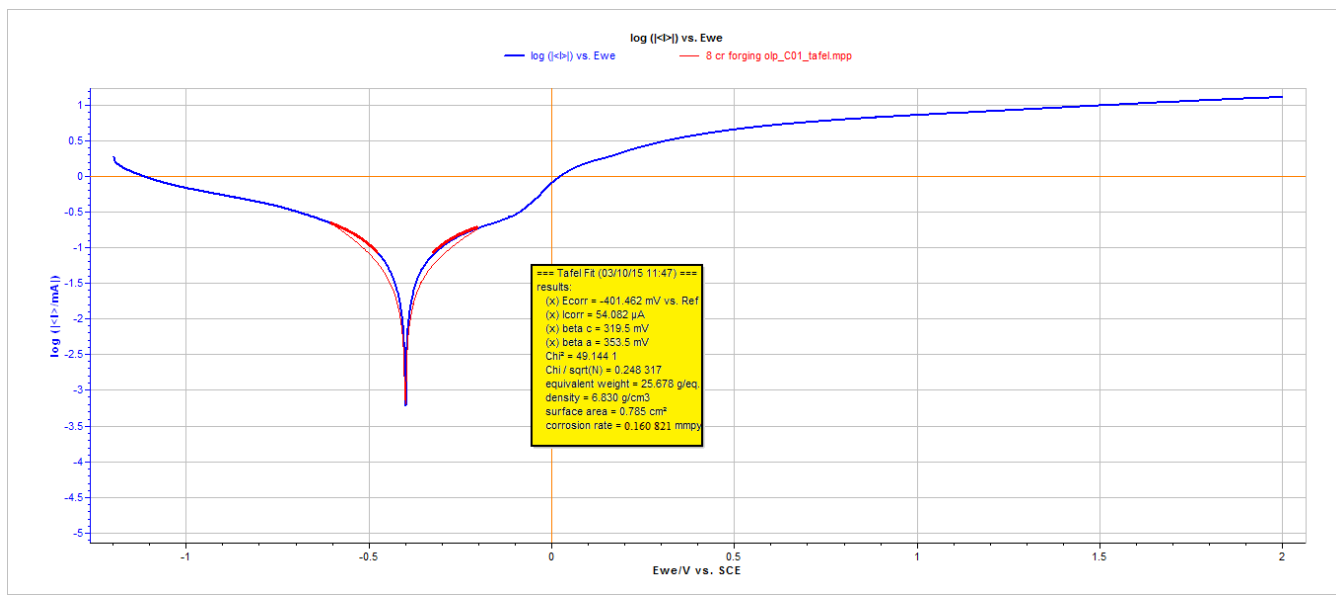

Figure 3: Tafel graph for $8 \% \mathrm{Cr}$ specimens. 


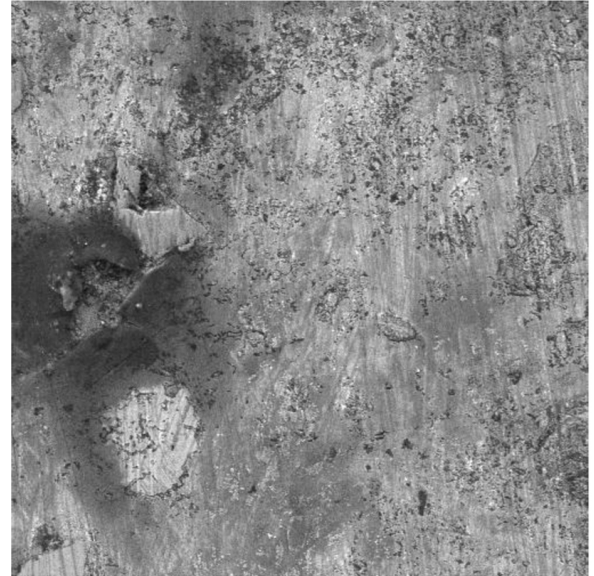

A

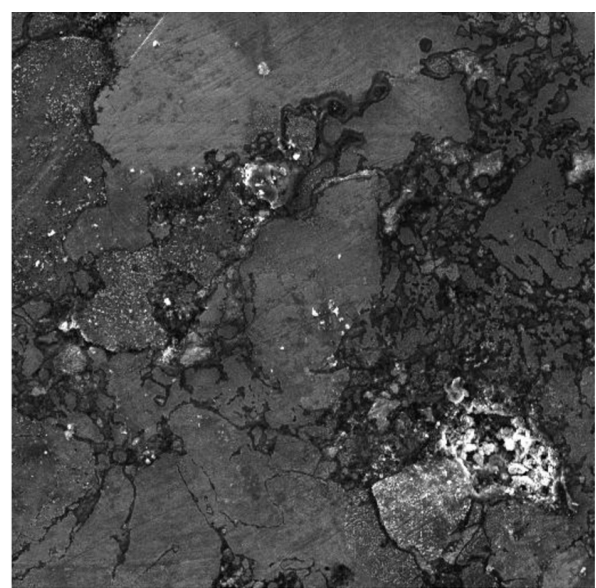

B

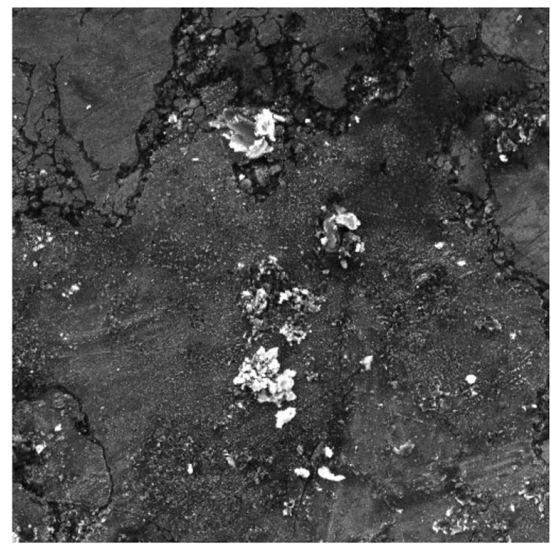

C

Figure 4: SEM images of corroded specimens $(20 \mu \mathrm{m})-(\mathrm{a}) 4 \% \mathrm{Cr},(\mathrm{b}) 8 \% \mathrm{Cr}$, (c) $12 \% \mathrm{Cr}$.

Table 5: Corrosion rate.

\begin{tabular}{lrrrr}
\hline Sample & Chromium \% & $\mathbf{E}_{\text {Corr }}(\mathbf{m V})$ & $\mathbf{I}_{\text {Corr }}(\mu \mathrm{A})$ & $\begin{array}{r}\text { Corrosion rate } \\
(\mathbf{m m} / \text { year) }\end{array}$ \\
\hline Specimen 1 & 4 & -498.2471 & 15.65 & 0.245 \\
Specimen 2 & 8 & -401.462 & 54.082 & 0.160 \\
Specimen 3 & 12 & -344.566 & 87.911 & 0.087 \\
\hline
\end{tabular}

\subsection{SEM analysis}

Generally, SEM shows the $\mathrm{Cu}$ rich-fcc $\alpha$ phase and some $\beta$ phase due to $\mathrm{Ni}, \mathrm{Cr}$ and Al. Also we can find intermetallic $\kappa$ phases. It is clear that the surface roughness increased more in the $4 \% \mathrm{Cr}$ sample and somewhat in $8 \%$ and $12 \%$ also due to corrosion as shown in Figure 4 . It is seen from the SEM images that the specimen corrodes at certain portions indicating the rupture of $\alpha$ and $\kappa$ phases. The porosity formed in the corroded areas is due to the dissolvation of $\mathrm{Al}$ in $\mathrm{Cu} \alpha$ matrix which will tend to more corrosion. The pitting corrosion occurs in the specimens in major areas. The precipitation free zone is not affected by corrosion. We also see that micro cracks developed in the specimen which propagates into the $\alpha$ phase. These micro cracks and cavities were formed at widely different locations. 


\section{Conclusion}

- The present developed $\mathrm{Cu}$ alloy has more mechanical and corrosion properties than already available in $\mathrm{NAB}$ alloys used in the propellers of ships, pipes, etc.

- The overall electrochemical behavior was like $\mathrm{Cu}-\mathrm{Ni}$ alloys and pure $\mathrm{Cu}$ due to the formation of thin oxide layer films. Due to the influence of $\mathrm{Cr}$ in the alloy, the material found is less likely to be attacked by biofouling.

- SEM analysis revealed that selective corrosion occurs in various $\kappa$ phases. The dissolution of $\mathrm{Al}$ in the $\mathrm{Cu}-$ rich $\alpha$ phase are less corroded.

\section{Acknowledgments}

We sincerely thank National Institute of Technology - Tiruchirappalli, India, for providing lab facilities for our research works.

\section{References}

[1] Culpan EA, Rose G. J. Mater. Sci. 1978, 13, 1647-1657.

[2] Lv Y, Hu M, Wang L, Xu X, Han Y, Lu W. J. Mater. Res. 2015, 1, 1-8.

[3] Culpan EA, Rose C. Br. Corros. J. 1979, 14, 160-166.

[4] Ferrara R], Caton TE. Mater. Perf. 1982, 21, 30-34.

[5] Lorimer CW, Hasan F, Iqbal ], Ridley N. Br. Corros. ]. 1986, 21, 244-248.

[6] Al-Hashem A, Riad W. Mater. Charact. 2002, 48, 37-41.

[7] Song QN, Zheng YG, Ni DR, Ma ZY. Corrosion Science. 2015, 92, 95-103. DOI: 10.1016/j.corsci.2014.11.039.

[8] Wharton ]A, Stokes KR. Electrochimica Acta. 2008, 53 (5), 2463-2473. DOI: 10.1016/j.electacta.2007.10.047.

[9] Chengxiwang A, Chuanhai Jiang A, Ze Chai A, Ming Chen A, Lianbowang A, Vincent ]i B. Surf. Coat. Technol. 2017, 313, 136-142.

[10] Wharton JA, Barik RC, Kear G, Wood R]K, Stokes KR, Walsh FC. Corros. Sci. 2005, 47, 3336-3367.

[11] Hasan F, Jahanafrooz A, Lorimer CW, Ridley N. Met. Trans. A 1982, 13a, 1337-1345.

[12] Chen R-P, Liang Z-Q, Zhang W-W, Zhang D-T, Luo Z-Q, Li Y-Y. Trans. Nonferr. Met. Soc. China 2007, 17, 1254-1258.

[13] Thossatheppitak B, Uthaisangsuk V, Mungsuntisuk P, Suranuntchai S, Manonukul A. Mater. Sci. Eng. A 2014, 604, 183-190.

[14] Lloyd DM, Lorimer CW, Ridley N. Met. Technol. 1980, 7, 114-119.

[15] Basumatary ], Wood R]K. Tribology International 2017. DOI: 10.1016/j.triboint.2017.08.006.

[16] Krogstad HN, Johnsen R. Corrosion Science. 2017, 121, 43-56. DOI: 10.1016/j.corsci.2017.03.016.

[17] Wu Z, Cheng YF, Liu L, Lv W, Hu W. Corrosion Science. 2015, 98, 260-270. DOI: 10.1016/j.corsci.2015.05.037.

[18] Nakhaie D, Davoodi A, Imani A. Corrosion Science. 2014, 80, 104-110. DOI: 10.1016/j.corsci.2013.11.017.

[19] Song QN, Zheng YG, Ni DR, Ma ZY. Corrosion Science. 2015, 92, 95-103. DOI: 10.1016/j.corsci.2014.11.039.

[20] Klassen RD, Roberge PR, Hyatt CV. Electrochimica Acta. 2001, 46 (24-25), 3705-3713. DOI: 10.1016/S0013-4686(01)00652-1.

[21] Wood R]K. Wear. 2006, 261 (9), 1012-1023. DOI: 10.1016/j.wear.2006.03.033. 